\title{
Multidecadal Trends in Thickness Temperature, Surface Temperature, and 700-hPa Temperature in the Mount Fuji Region, Japan, 1965-2016
}

\author{
YuKITOMO TSUTSUMI \\ Meteorological Research Institute, Japan Meteorological Agency, Tsukuba, Ibaraki, Japan
}

(Manuscript received 12 April 2018, in final form 11 July 2018)

\begin{abstract}
In studies of global warming, increases in tropospheric temperature as well as increases in surface temperature have attracted attention. Simulations of trends in these two temperatures appear to differ from trends in observations by surface sites, radiosondes, and satellites. Moreover, observation errors such as uncertainties in measurement precision and calibration, environmental changes, and the reorganization of network sites hamper the ability to quantify these influences on temperature trends. This paper presents multidecadal (1965-2016) trends in lower-tropospheric temperature for south-central Japan derived from thickness temperature, a measurement based on pressure data from exactly known altitudes at the summit of Mount Fuji $(3776 \mathrm{~m})$ and surrounding meteorological sites. The resulting trend is compared with the trends in surface temperature and in the temperature at $700 \mathrm{hPa}$ measured by radiosonde. Although surface temperature increased faster than tropospheric (thickness) temperature in the study area for the 1965-2016 period, tropospheric temperature increased faster than surface temperature after 1985. Additionally, it is found that radiosonde data are not appropriate for determining the temperature trend at constant altitudes because atmospheric warming raises the altitude of the pressure levels.
\end{abstract}

\section{Introduction}

The quality of the evidence of increasing temperature is a long-standing issue for studies of global warming. Precise and consistent long-term measurements of temperature are not easy, even on a regional scale. Temperature data may include errors in calibrations and visual reading, especially in old data. Measurements at ground sites may be influenced by environmental changes such as urbanization effects and alterations in wind ventilation (exposure) as shown by Klotzbach et al. (2009). Furthermore, regional-mean multidecadal temperatures derived from observation networks may be affected by bias resulting from reorganizations of observation sites in networks. Therefore, multidecadal surface temperature trends could be affected by biases and uncertainties due to nonspatially representative influences (Klotzbach et al. 2009 and references therein).

Thickness is a well-known meteorological quantity, defined by pressures and altitudes at two atmospheric levels and interpreted as the mean temperature of the layer between the levels. Given the pressures at two

\footnotetext{
Corresponding author: Yukitomo Tsutsumi, y-tsutsumi@mri-jma go.jp
}

altitudes, the mean temperature of the intervening layer (thickness temperature $T$ ) is

$$
T=\frac{g\left(z_{2}-z_{1}\right)}{R \ln \left(P_{1} / P_{2}\right)}
$$

where $g$ is gravitational acceleration, $R$ is the universal gas constant, and $z_{1,2}$ and $P_{1,2}$ are the altitudes and pressures at two levels, respectively.

Although calculations of thickness temperature cannot incorporate short-time adiabatic heating such as that produced from convective cumulus, this shortcoming can be neglected in determining temperature trends that have longer time scales. Pressure data, in general, have better precision than temperature data because pressure measurements and their calibration principles are simpler and more robust. Variations of pressure can be well characterized at synoptic scales, as shown by synoptic charts, and pressure measurements are little affected by changes in the surrounding environment. These features make thickness temperature advantageous for recording consistent long-term temperature trends in atmospheric layers with well-defined vertical boundaries.

Thickness temperatures are especially accurate when pressure data from a mountain site can be combined 


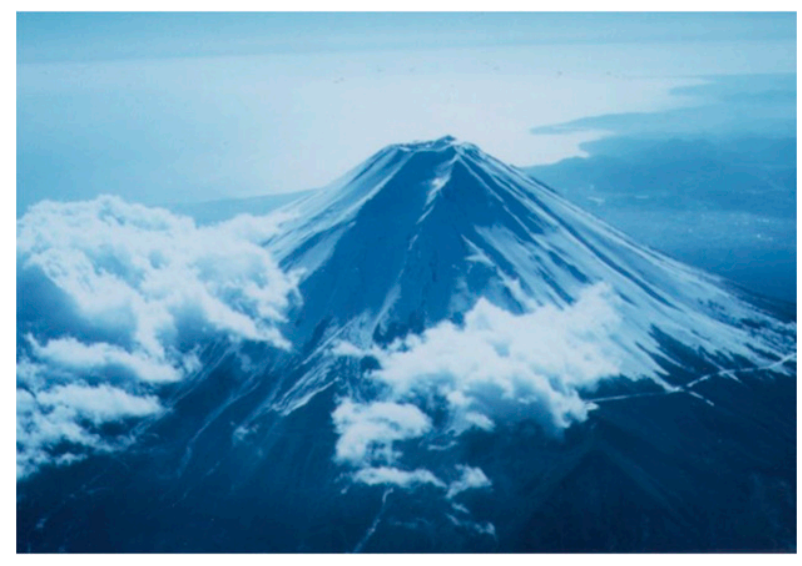

FIG. 1. Aerial photograph of Mount Fuji. Photo courtesy J. Koike.

with observations from surrounding low-elevation surface sites because the altitudes of all observations are exactly known. Mount Fuji (elevation of $3776 \mathrm{~m}$ ) is an isolated conical volcano in south-central Japan with steeply sloping flanks (Fig. 1). The observation records from the summit of Mount Fuji are relatively uninfluenced by the planetary boundary layer, and pollutant observations made from the summit are accepted as representative of the middle troposphere (Tsutsumi et al. 1994; Tsutsumi 2018). The thickness temperatures derived from pressure measurements by the network that includes the Mount Fuji observatory, thus, acceptably represents the mean temperature of the tropospheric layer below Mount Fuji.

In this study, multidecadal trends in thickness temperature were derived from pressure measurements made at Mount Fuji and four other meteorological sites in south-central Japan from 1965 through 2016. The area-averaged trends were then compared with the corresponding trends of surface temperature at the summit of Mount Fuji, mean surface temperature in the study area, mean surface temperature for Japan, and temperature at the 700 -hPa level measured by radiosonde at the nearest aerological site to clarify the robust temperature trends in the Mount Fuji region and evaluate the relationships between them.

\section{Methods}

\section{a. Pressure measurement and derivation of thickness-temperature trend}

Daily mean pressures at the Mount Fuji observatory (3775.1 $\mathrm{m}$ above sea level) and four surface sites within about $50 \mathrm{~km}$ of the peak (Table 1; Fig. 2) were used to calculate thickness temperatures from 1965 through 2016.
The precisions of the barometers at all sites were within $\pm 0.1 \mathrm{hPa}$ for the automated weather system and Japan Meteorological Agency (JMA) JMA-80 and JMA-95 systems, and within $\pm 0.15 \mathrm{hPa}$ for the JMA-10 system. These instruments are regularly maintained and calibrated according to the standard procedures of the JMA. It was important to consider the relocation history of the barometers (Table 2), as thickness temperature is sensitive to changes in altitude or pressure; a change of $1 \mathrm{~m}$ corresponds to about $0.08^{\circ} \mathrm{C}$. These changes were incorporated in the calculations of thickness temperatures.

The daily mean thickness temperatures at Mount Fuji and surrounding sites were derived from the daily mean pressures, which are obtained from the average of every hour of data. They are published by the JMA (http://www. data.jma.go.jp/obd/stats/etrn/view/daily_s1.php). The daily mean pressures are averaged into monthly and yearly means, from which the yearly anomalies in thickness temperature were calculated with respect to the normal average (1981-2010). The trends in thickness temperature derived in this study are based on these anomalies. Because pressure observations were not made at the Mount Fuji observatory from 9 June to 2 July 2014, the yearly mean for 2014 was not used in deriving the trend in thickness temperature. The trends in this paper were derived by the MAKESENS application, which is based on the Mann-Kendall trend test (Sirois 1998).

\section{b. Surface temperature measurement and derivation of trends}

Trends in surface temperature at the Mount Fuji observatory were based on the yearly mean temperatures published by the JMA (http://www.data.jma.go.jp/obd/ stats/etrn/index.php). The replacement histories of observation systems in the observation sites and the precision of thermometers are listed in Table 3. Concerning the homogeneity of meteorological observations, the JMA controls data quality according to the guidelines (JMA 2005). Furthermore, the JMA judges statistical discontinuity of observations using the following conditions (JMA 2005):

- It is judged that observations statistically discontinue if observation sites move in horizontal distance over $500 \mathrm{~m}$ or change in altitude over $5 \mathrm{~m}$.

- Even if relocations of the site do not satisfy the condition, it is judged that observations statistically discontinue if environments around the site change markedly.

- It is judged to statistically continue in the case that influences of relocation are sufficiently small even if the condition is satisfied. 
TABLE 1. Locations of observation sites.

\begin{tabular}{lcccr}
\hline \multicolumn{1}{c}{ Site } & Latitude $\left({ }^{\circ} \mathrm{N}\right)$ & Longitude $\left({ }^{\circ} \mathrm{E}\right)$ & Altitude $(\mathrm{m})$ & Distance from Mount Fuji $(\mathrm{km})$ \\
\hline Mount Fuji & 35.35 & 138.73 & 3775.1 & 0 \\
Kawaguchiko & 35.50 & 138.76 & 859.6 & 16 \\
Koufu & 35.67 & 138.55 & 272.8 & 37 \\
Shizuoka & 34.98 & 138.40 & 14.1 & 52 \\
Mishima & 35.12 & 138.93 & 20.7 & 34 \\
\hline
\end{tabular}

- Even if the observation sites are not moved, it is judged that observations statistically discontinue if environments around site change markedly.

The observation data used in the trend analyses were those in which any statistical discontinuity is not detected. Because temperature measurements were not made at the Mount Fuji observatory from 16 July to 20 August 1970 and from 9 June to 2 July 2014, the yearly means for 1970 and 2014 were not used in deriving the trend.

To derive the trend in mean (areal average) surface temperature at the other sites in the study area, yearly mean surface temperatures for these sites were converted to mean (areal average) surface temperatures for the study area, and trends were then derived from anomalies with respect to the normal average in the study area. The trend in mean temperature for Japan was derived from the yearly mean temperature anomalies from 15 sites (http://www.data.jma.go.jp/cpdinfo/temp/list/an_jpn.html) that were also used to derive the official mean temperature in Japan by the JMA (e.g., JMA 2017).

\section{c. Temperature measurement at $700 \mathrm{hPa}$ by radiosonde and derivation of trends}

The temperature trend in the middle troposphere $(700 \mathrm{hPa})$ was derived from the radiosonde data over the Tateno station $\left(36.06^{\circ} \mathrm{N}, 140.125^{\circ} \mathrm{E}\right.$; see Fig. 2), part of the Global Climate Observing System Reference Upper Air Network and the closest aerological station to Mount Fuji $(145 \mathrm{~km})$. Long-term temperature trends based on radiosonde data were usually subject to adjustments (Christy and Norris 2006; Christy et al. 2007; Christy and Norris 2009; Guo and Ding 2011). The histories of sonde sensors and their biases were presented in Uesato et al. (2008), and Kobayashi (2016) showed $0.18^{\circ} \mathrm{Cdecade}^{-1}$ as a temperature trend between 1958 and 2014 at $850 \mathrm{hPa}$ over Tateno after the adjustment of temperature sensor biases.

However, neither temperature data before 1987 nor any adjusted data have been published over Tateno. In this paper, the temperature trend over Tateno was derived from yearly mean temperatures by the JMA monthly mean temperatures at $700 \mathrm{hPa}$ at $2100 \mathrm{Japan}$ standard time (JST) from 1987 through 2016 (http:// www.data.jma.go.jp/obd/stats/etrn/upper/view/monthly. php), in which any adjustment was not made. The reason for employing the 2100 JST dataset is to avoid the possible influence of solar radiation; however, the temperature trend for 0900 JST is only slightly stronger $\left(0.008^{\circ} \mathrm{Cdecade}^{-1}\right)$, and the variation is very similar.

\section{Results}

\section{a. Regional representativeness}

The yearly mean thickness temperatures differ among the sites in the study area. To evaluate these differences, yearly standard deviations of area mean of the thickness-temperature anomalies were calculated. Then the yearly series was averaged from 1965 through 2016. The resultant mean standard deviation was $0.08^{\circ} \mathrm{C}$, indicating that the thickness temperature faithfully represented the temperature of the lower troposphere in the study area. The comparisons that follow are based on the areal-average thickness temperatures.

\section{b. Yearly variation of running-mean temperature}

Figure 3a shows the yearly variations of the surface temperature anomaly at Mount Fuji, the surface

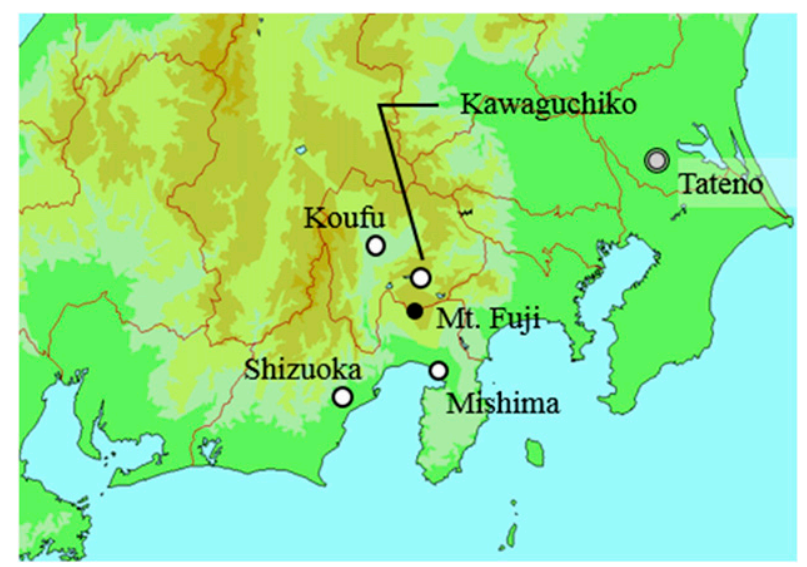

FIG. 2. Location map of south-central Japan showing observation sites. 
TABLE 2. Changes in barometer altitudes (m) at the observation sites.

\begin{tabular}{lccccccc}
\hline \hline Year & Month & Day & Mount Fuji & Kawaguchiko & Shizuoka & Mishima & Koufu \\
\hline 1965 & Jan & 1 & 3773.0 & 860.5 & 14.9 & 21.7 & 274.0 \\
1967 & Jan & 1 & - & - & 15.4 & - & - \\
1969 & Mar & 13 & - & - & - & - & 281.0 \\
1993 & Mar & 18 & - & - & - & - & - \\
2004 & Feb & 17 & - & - & 15.9 & - & 282.0 \\
2004 & Aug & 26 & 3778.0 & - & - & - & - \\
2005 & Feb & 1 & 2 & - & 861.3 & - & - \\
2005 & Dec & 21.9 & &
\end{tabular}

temperature anomaly in the study area, the thicknesstemperature anomaly in the study area, and the mean surface temperature anomaly in Japan from 1965 through 2016. Because the wide interannual variation in these anomalies obscures long-term trends, another plot was prepared based on 9-yr running means (Fig. 3b). These plots showed that trends in temperature anomalies in the study area were not monotonic. In Fig. 3b, the thickness temperature in the study area and the surface temperature at Mount Fuji decreased until 1985 and then increased after 1985. On the other hand, the surface temperature in the study area did not decrease notably before 1985, and the mean temperature in Japan decreased only slightly before 1985 . Both the thickness temperature and the surface temperature in the study area increased after 1985. The surface temperatures in the study area and Japan leveled off from 2002 to 2009, coinciding with the hiatus in global temperature rise (e.g., Medhaug et al. 2017 and references therein). However, the thickness temperature increased with some variations during that period.

\section{c. Temperature trends}

Given the sharp inflection in all temperature records in 1985 (Fig. 3b), the long-term temperature trends (1965-2016) and the recent temperature trend (19852016) are discussed separately. For the discussion, the temperature trends during the period after the inflection and before the hiatus (1985-2000) were also derived (Table 4).

\section{1) $1965-2016$}

The trends of thickness temperature and surface temperature in the study area during 1965-2016 are shown in Table 4 and Fig. 4. In the study area, the thickness temperature increased by $0.22^{\circ} \mathrm{Cdecade}^{-1}$, and the surface temperature increased faster, by $0.31^{\circ} \mathrm{C} \mathrm{decade}^{-1}$. The thickness-temperature anomaly in the study area decreased distinctly, unlike the surface temperature anomaly, during the $1965-85$ period (Fig. 3b). The surface temperature anomaly at Mount Fuji also decreased before 1985.

The trend in thickness temperature appears to be weaker than the trend in surface temperature in the study area because surface temperatures in the study area decreased less than thickness temperatures during 1965-85, the first part of the study period (Fig. 3b).

\section{2) $1985-2016$}

Thickness temperature and surface temperature both rose in the study area during 1985-2016 (Table 4; Fig. 5). Unlike the case for 1965-2016, however, the trend in thickness temperature $\left(0.40^{\circ} \mathrm{Cdecade}^{-1}\right)$ was stronger than the trend in surface temperature $\left(0.30^{\circ} \mathrm{Cdecade}^{-1}\right)$. Yet during $1985-2000$, the period preceding the temperature hiatus, the trend in surface

TABLE 3. Replacement date of meteorological observation system and precision of thermometers in the sites. JIS is Japanese Industrial Standards.

\begin{tabular}{|c|c|c|c|c|}
\hline Type/site & Automated weather system & JMA-80 & JMA-95 & JMA-10 \\
\hline Mount Fuji & 5 Oct 1964 & 30 Sep 1985 & 26 Aug $2004^{a}$ & 7 Aug 2014 \\
\hline Shizuoka & 1 May 1973 & 16 Feb 1984 & 22 Feb 1996 & 10 Mar 2011 \\
\hline Mishima & 1 May 1974 & 23 Dec 1988 & 31 Aug 2001 & 30 Oct 2014 \\
\hline Kawaguchiko & 1 May 1974 & 6 Feb 1988 & 17 Sep 2003 & 23 Oct 2014 \\
\hline Koufu & 1 May 1973 & 4 Feb 1983 & $21 \mathrm{Feb} 1996$ & $24 \operatorname{Mar} 2011$ \\
\hline Temperature precision & $\pm 0.13^{\circ} \mathrm{C}$ & JIS class 0.2 & JIS JPt100 class 0.2 & JIS C1604 class A \\
\hline Reference & JMA (1973) & JMA (1984) & JMA (1996) & JMA (2010) \\
\hline
\end{tabular}

${ }^{\mathrm{a}}$ The observation system is not JMA-95 but an automated weather system for Mount Fuji, with a temperature precision in accordance with JIS C 1604-1997. 

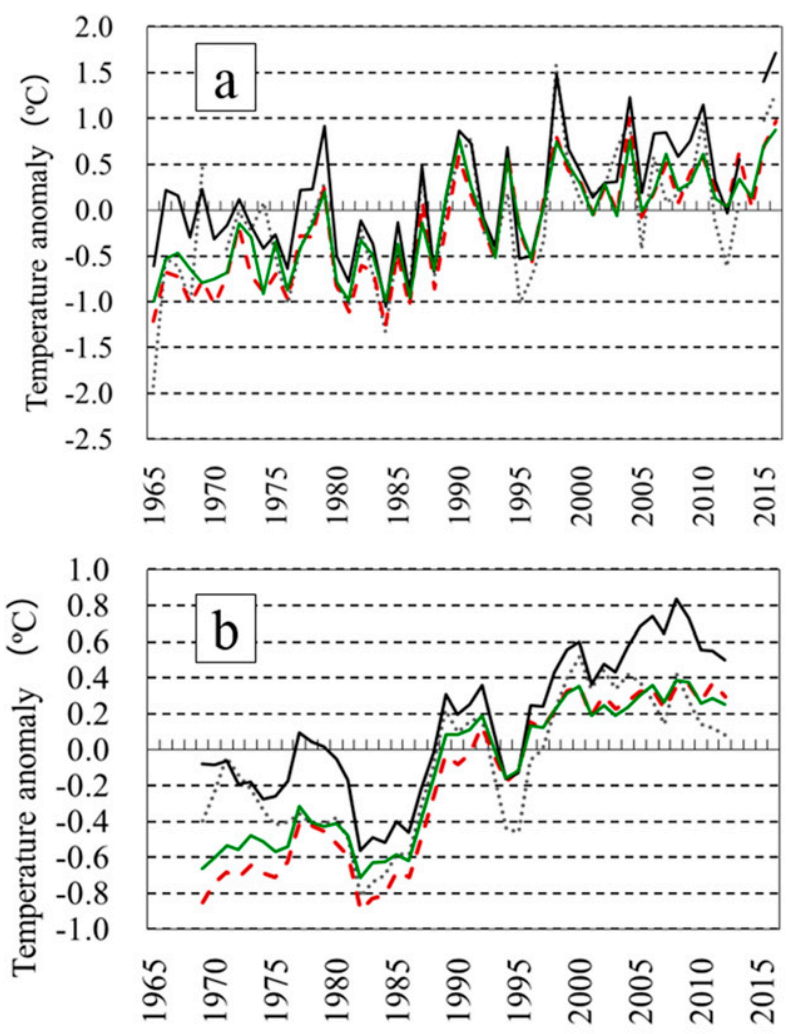

….. Surface temperature anomaly at Mt. Fuji

- - Surface temperature anomaly in study area

— Thickness temperature anomaly in study area

-Mean temperature anomaly of Japan

FIG. 3. (a) Annual means and (b) 9-yr running means of the surface temperature anomaly at Mount Fuji, mean surface temperature anomaly of the study area, mean thickness-temperature anomaly of the study area, and mean surface temperature anomaly of Japan.

temperature $\left(0.60^{\circ} \mathrm{C}\right.$ decade $\left.^{-1}\right)$ was stronger than the trend in thickness temperature $\left(0.48^{\circ} \mathrm{Cdecade}^{-1}\right.$; Table 4). From these results, it appears that the trend of thickness temperature exceeded that of surface temperature in the study area during 1985-2016 because the thickness temperature continued to increase during 2001-10, the period of hiatus in surface temperature (Fig. 3b).

\section{3) THE 1985 TURNING POINT}

As shown in the running means of surface temperature and thickness temperature (Fig. 3b), the year 1985 is a turning point from decreasing to increasing trends. Consistent with this finding, JMA (2017) also showed the large increase after around 1985 in 5-yr running-mean surface temperature in Japan (their Figs. 2.1-3).
TABLE 4. Trends of thickness temperature, surface temperature, and temperature at $700 \mathrm{hPa}$.

\begin{tabular}{clc}
\hline \hline Period & \multicolumn{1}{c}{$\begin{array}{c}\text { Temperature type } \\
\text { and location }\end{array}$} & $\begin{array}{c}\text { Trend } \\
\left({ }^{\circ} \mathrm{Cdecade}^{-1}\right)\end{array}$ \\
\hline \multirow{2}{*}{ 1965-2016 } & Thickness in study area & 0.22 \\
& Surface in study area & 0.31 \\
& Surface at Mount Fuji & 0.25 \\
& Surface in Japan & 0.25 \\
$1985-2000$ & Thickness in study area & 0.48 \\
& Surface in study area & 0.60 \\
& Surface at Mount Fuji & 0.37 \\
\multirow{1}{*}{$1985-2016$} & Surface in Japan & 0.56 \\
& Thickness in study area & 0.40 \\
& Surface in study area & 0.30 \\
& Surface at Mount Fuji & 0.27 \\
\multirow{2}{*}{$1987-2016$} & Surface in Japan & 0.24 \\
& Tateno (700 hPa) over Tateno & 0.14 \\
\hline
\end{tabular}

Variations of solar radiation at the ground surface can affect surface temperature. It is well known that global dimming changed to global brightening in the late 1980s (e.g., Wild et al. 2005; Streets et al. 2006) and global temperatures increased after the global dimming (Wild 2009). The 5-yr running mean of solar radiation in Japan (Fig. 4 in Ohmura 2009) displays a similar pattern of decrease followed by an increase; however, the minimum occurred in 1991, whereas the minimum in the 5-yr running-mean thickness temperature in the study area occurred in 1982 (this study; data not shown). Moreover, the yearly variations in solar radiation and thickness temperature were anticorrelated at times. Thus, the atmospheric temperature in the study is not strongly affected by the solar radiation in Japan.

As the study area is close to the Pacific Ocean, the surface temperatures could be affected by sea surface

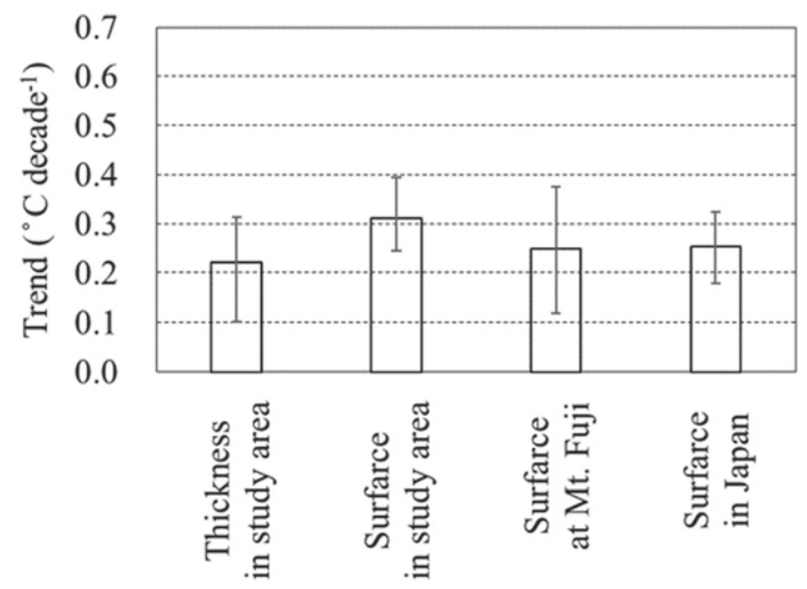

FIG. 4. Trends of mean thickness temperature in the study area, mean surface temperature in the study area, surface temperature at Mount Fuji, and mean surface temperature in Japan from 1965 through 2016. Error bars indicate the $95 \%$ confidence interval. 


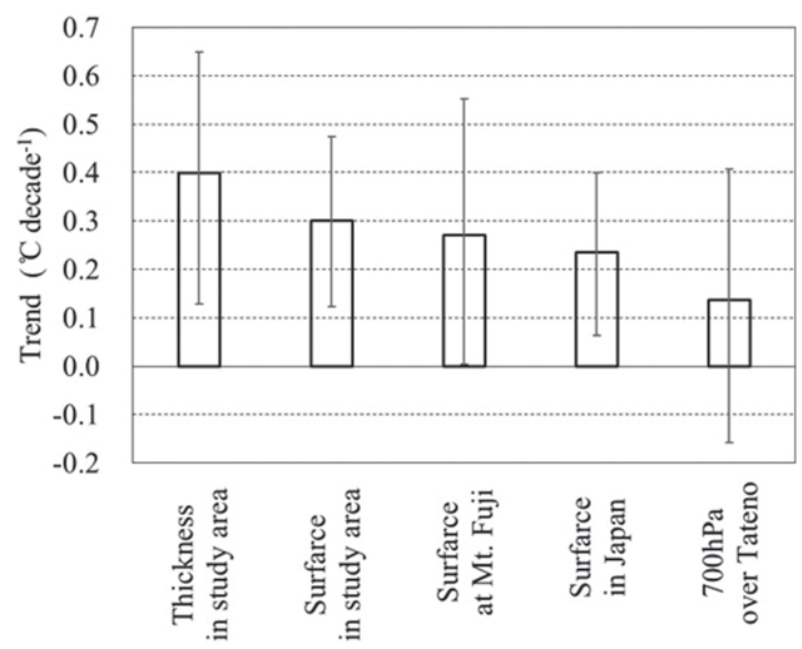

FIG. 5. Trends of mean thickness temperature in the study area, mean surface temperature in the study area, surface temperature at Mount Fuji, and mean surface temperature in Japan from 1985 through 2016 and the temperature trend at $700 \mathrm{hPa}$ over Tateno from 1987 through 2016. Error bars indicate the 95\% confidence interval.

temperature near the area. It is found that the temperatures in this area, especially the surface temperature, vary in line with the sea surface temperature to the south of the area. Figure 6 shows the relationship between the yearly surface temperature anomaly in study area and the sea surface temperature anomaly to south of study area. In the analysis, the sea surface temperature anomaly data employed and the targeted ocean area are published on the JMA website (http://www. data.jma.go.jp/kaiyou/data/shindan/a_1/japan_warm/cfig/ warm_area.html?area $=\mathrm{M}$ ). They show the high correlation coefficients in yearly variation (0.79) and in 9-yr running mean (0.94). Although surface temperatures are affected by many meteorological factors, the surface temperature variations in the area have a close relationship with the sea surface temperature to the south of the study area.

\section{4) TEMPERATURE AND PRESSURE TRENDS AT MOUNTAIN SUMMITS}

Toumi et al. (1999) inferred decadal temperature trends at a worldwide set of mountain sites by using the "effective surface temperature," defined by the difference between mountain pressure data and a gridded dataset of sea level pressures assuming a constant lapse rate. The mean temperature trend from their seven mountain sites that showed trends in the latter half of the last century (1950s-90s; their Table 1) was $0.31^{\circ} \mathrm{C}$ decade $^{-1}$. They noted the possibility that the mean temperature of the layer below the mountain sites increased more rapidly than the surface temperature

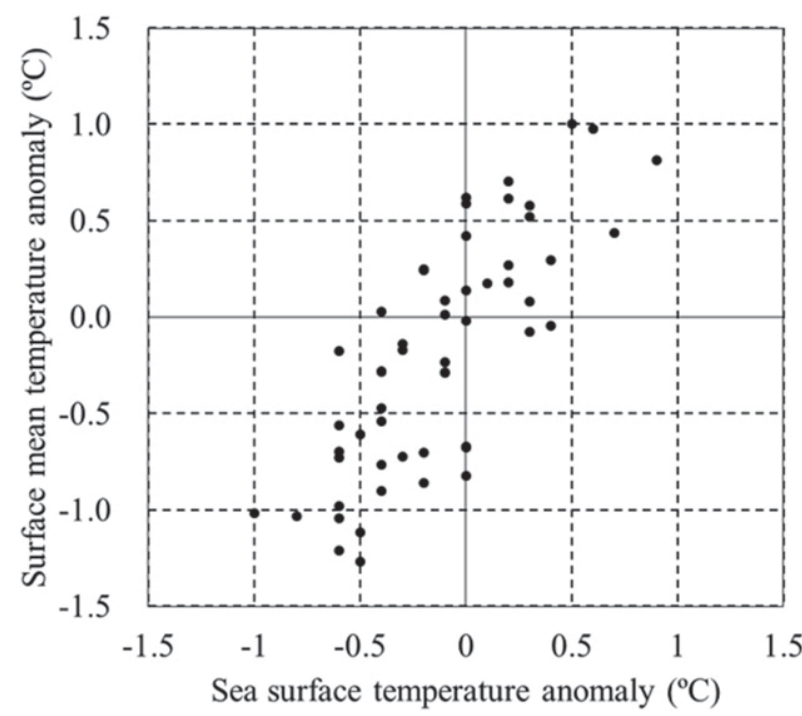

FIG. 6. Scatterplot between yearly surface temperature anomaly in the study area and yearly sea surface temperature anomaly to the south of the study area.

near sea level. In the area of this study, however, the trend in surface temperature near sea level $\left(0.34^{\circ} \mathrm{Cdecade}^{-1}\right)$ was stronger than the trend in thickness temperature $\left(0.11^{\circ} \mathrm{Cdecade}^{-1}\right)$ calculated for the 1965-2000 period (data not shown).

Observations show that the pressure at the Mount Fuji observatory significantly increased by $0.15 \mathrm{hPa}$ decade ${ }^{-1}$ from 1965 through 2016 (Fig. 7; Table 5), although the altitude of the barometer rose by $5 \mathrm{~m}$ in 2004 (Table 2). Please note that the pressure trend was not adjusted after the relocation of the barometer in 2004, which indicates the actual pressure trend at the same altitude was larger than $0.15 \mathrm{hPadecade}^{-1}$. On the other hand, pressures at the surface sites near sea level showed no increase (Table 5). The pressure increase at the summit of Mount Fuji, thus, reflects an increase in thickness temperature in the layer below the summit.

\section{5) Temperature trend AT $700 \mathrm{HPA}$}

The temperature trend measured at $700 \mathrm{hPa}$ by radiosonde over the Tateno station at 2100 JST from 1987 to 2016 is the weakest determined in this study $\left(0.14^{\circ} \mathrm{C}\right.$ decade $\left.^{-1}\right)$, although it is not statistically significant (Table 4; Fig. 5). The trend of increasing pressure at the Mount Fuji observatory shows that the altitudes of constant pressure levels in the middle troposphere have risen in the study area. Because such a rise can be expected to lower the temperature at constant pressure levels, such as $700 \mathrm{hPa}$, radiosonde observations are not appropriate for determining temperature trends at constant pressure levels. 


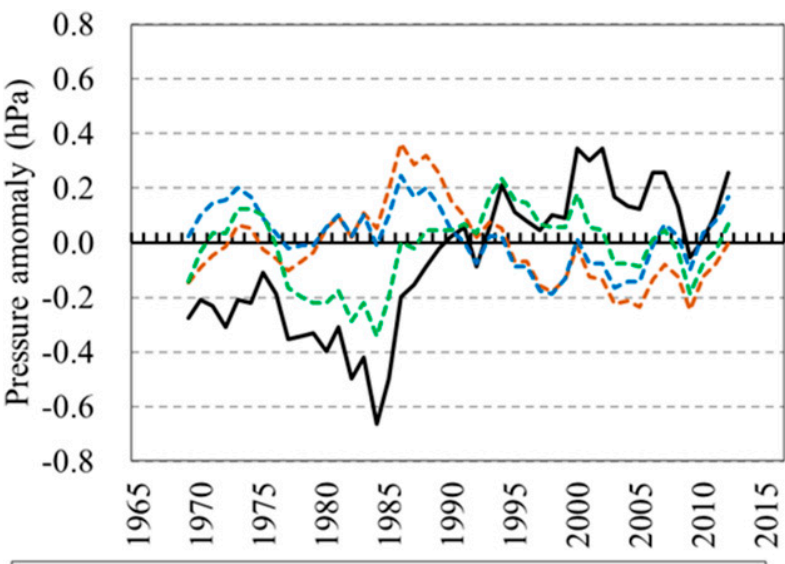

-Mt. Fuji ----Shizuoka ----Mishima----Kawaguchiko

FIG. 7. The 9-yr running mean of annual pressure anomaly observed at the summit of Mount Fuji and surface-pressure anomalies of the study area.

\section{Discussion}

Climate models have projected that the maximum temperature increases caused by the greenhouse effect will occur in the middle troposphere (Santer et al. 2005 and references therein). However, the temperature trends in radiosonde and satellite observations have been weaker than trends in surface temperature, as reported for the tropical troposphere (Santer et al. 2005) and for the lower troposphere (Klotzbach et al. 2009).

Klotzbach et al. (2009) suggested that a growing number of studies found biases and uncertainties due to nonspatially representative influences in the assessment of multidecadal surface temperature trends. In the Mount Fuji study area, however, pressure measurements are hardly affected by environmental changes, and the distribution of observation sites does not appreciably affect the trends in thickness temperature, as shown in section 3a. In this trend analysis, therefore, the biases and uncertainties in temperature trends cited by Klotzbach et al. (2009) are considered negligible.

For 1965-2016, the trend in thickness temperature in the study area $\left(0.22^{\circ} \mathrm{C}\right.$ decade $\left.^{-1}\right)$ was almost the same as the trend in surface temperature at the Mount Fuji observatory $\left(0.25^{\circ} \mathrm{Cdecade}^{-1}\right)$, which represents the lower troposphere in the study area, but the trend in surface temperature in the study area $\left(0.31^{\circ} \mathrm{Cdecade}{ }^{-1}\right)$ was stronger (Table 4; Fig. 4). This result is consistent with those of Klotzbach et al. (2009). However, for 1985-2016, the trend in thickness temperature $\left(0.40^{\circ} \mathrm{C}\right.$ decade $\left.^{-1}\right)$ was stronger than the trend in surface temperatures in the study area at the Mount Fuji observatory and in Japan as a whole (Table 4; Fig. 5). This result is consistent with projections from climate models (Tett et al. 2002; Santer
TABLE 5. Trends of pressures at the summit of Mount Fuji and surface sites. An asterisk indicates significance at the $95 \%$ level. In the trends, barometer relocations are not taken into consideration. Koufu is excluded because the altitude of the barometer significantly rose in 2004.

\begin{tabular}{lcc}
\hline \hline \multicolumn{1}{c}{ Site (altitude) } & $\begin{array}{c}\text { Pressure trend } \\
\left(\text { hPa decade }^{-1}\right)\end{array}$ & Significance \\
\hline Shizuoka $(14.9 \mathrm{~m})$ & 0.00 & - \\
Mishima $(21.7 \mathrm{~m})$ & 0.00 & - \\
Kawaguchiko $(860.5 \mathrm{~m})$ & 0.06 & - \\
Mount Fuji $(3775.1 \mathrm{~m})$ & 0.15 & $*$ \\
\hline
\end{tabular}

et al. 2005). The evidence from this study area, then, suggests that around 1985, the trends in surface and thickness temperatures changed, after which thickness temperatures increased faster than surface temperatures.

This discussion excludes consideration of temperature trends based on radiosonde data because their observation altitudes, performed at constant pressure levels, have been found to be affected by atmospheric warming. On the other hand, trends in thickness temperatures, based on pressure measurements at exact altitudes, are generally considered to be a robust index of long-term temperature change in the troposphere because of the high precision, consistent stability, and synoptic extent of pressure measurements.

\section{REFERENCES}

Christy, J. R., and W. B. Norris, 2006: Satellite and VIZ-radiosonde intercomparisons for diagnosis of nonclimatic influences. J. Atmos. Oceanic Technol., 23, 1181-1194, https://doi.org/ 10.1175/JTECH1937.1.

— , and — 2009: Discontinuity issues with radiosonde and satellite temperatures in the Australian region 1979-2006. J. Atmos. Oceanic Technol., 26, 508-522, https://doi.org/ 10.1175/2008JTECHA1126.1.

,,-- R. W. Spencer, and J. J. Hnilo, 2007: Tropospheric temperature change since 1979 from tropical radiosonde and satellite measurements. J. Geophys. Res., 112, D06102, https:// doi.org/10.1029/2005JD006881.

Guo, Y., and Y. Ding, 2011: Impacts of reference time series on the homogenization of radiosonde temperature. Adv. Atmos. Sci., 28, 1011-1022, https://doi.org/10.1007/s00376-010-9211-3.

JMA, 1973: Calibration system for thermometer and hygrometer for remote system (in Japanese). Sokkojihou, 40, 156-158.

- 1984: Outline of the JMA-80 surface meteorological observation equipment (in Japanese). Sokkojihou, 51, 331-346. 1996: Experiment of platinum resistance thermometers (in Japanese). Sokkojihou, 63, 253-256.

- 2005: Explanation of JMA statistical guideline of observations (in Japanese). JMA, http://www.data.jma.go.jp/obd/ stats/data/kaisetu.

- 2010: Basic design for thermometer in JMA-10. Technical materials for JMA-10 (in Japanese). JMA Rep., 6 pp.

_, 2017: Climate change monitoring report 2016. JMA Rep., 93 pp., https://www.jma.go.jp/jma/en/NMHS/ccmr/ccmr2016_low.pdf. 
Klotzbach, P. J., R. A. Pielke Sr., R. A. Pielke Jr., J. R. Christy, and R. T. McNider, 2009: An alternative explanation for differential temperature trends at the surface and in the lower troposphere. J. Geophys. Res., 114, D21102, https://doi.org/ 10.1029/2009JD011841; Corrigendum, 115, D01107, https:// doi.org/10.1029/2009JD013655.

Kobayashi, E., 2016: Temperature trend considering historical changes of radiosonde (Part 2) (in Japanese). J. Aerol. Obs., 74, 17-26.

Medhaug, I., M. B. Stolpe, E. M. Fischer, and R. Knutti, 2017: Reconciling controversies about the 'global warming hiatus.' Nature, 545, 41-47, https://doi.org/10.1038/nature22315.

Ohmura, A., 2009: Observed decadal variations in surface solar radiation and their causes. J. Geophys. Res., 114, D00D05, https://doi.org/10.1029/2008JD011290.

Santer, B. D., and Coauthors, 2005: Amplification of surface temperature trends and variability in the tropical atmosphere. Science, 309, 1551-1556, https://doi.org/10.1126/science.1114867.

Sirois, A., 1998: A brief and biased overview of time series analysis or how to find that evasive trend. GAW Research and Monitoring Rep. 133 and WMO/TD 956.

Streets, D. G., Y. Wu, and M. Chin, 2006: Two-decadal aerosol trends as a likely explanation of the global dimming/brightening transition. Geophys. Res. Lett., 33, L15806, https://doi.org/10.1029/ 2006GL026471.
Tett, S. F. B., and Coauthors, 2002: Estimation of natural and anthropogenic contributions to twentieth century temperature change. J. Geophys. Res., 107, 4306, https://doi.org/10.1029/ 2000JD000028.

Toumi, R., N. Hartell, and K. Bignell, 1999: Mountain station pressure as an indicator of climate change. Geophys. Res. Lett., 26, 1751-1754, https://doi.org/10.1029/ 1999GL900351.

Tsutsumi, Y., 2018: Characterization of ozone in the middle troposphere over Japan from 6 years of observations at the summit of Mount Fuji (3776 m). Pap. Meteor. Geophys., 67, 45-56, https://doi.org/10.2467/mripapers.67.45.

_ , Y. Zaizen, and Y. Makino, 1994: Tropospheric ozone measurement at the top of Mt. Fuji. Geophys. Res. Lett., 21, 17271730, https://doi.org/10.1029/94GL01107.

Uesato, I., S. Ito, M. Kumamoto, R. Shigebayashi, and M. Nakamura, 2008: Temperature trend considering historical changes of radiosonde (Part 1) (in Japanese). J. Aerol. Obs., 68, 15-22.

Wild, M., 2009: Global dimming and brightening: A review. J. Geophys. Res., 114, D00D16, https://doi.org/10.1029/ 2008JD011470.

— , and Coauthors, 2005: From dimming to brightening: Decadal changes in solar radiation at Earth's surface. Science, 308, 847850, https://doi.org/10.1126/science.1103215. 